\title{
Management of Inflammatory Arthritis in pregnancy: a National Cross-Sectional Survey of Canadian rheumatologists
}

\author{
Mary A. De Vera ${ }^{1,2,3^{*}}$ (D, Corisande Baldwin ${ }^{4}$, Nicole W. Tsao ${ }^{1,2,3}$, Alyssa Howren ${ }^{1,2,3}$, Glen S. Hazlewood ${ }^{2,5}$,
} Nevena Rebić, ${ }^{1,2,3}$ and Stephanie Ensworth ${ }^{4}$

\begin{abstract}
Background: With improved therapies and management, more women with inflammatory arthritides $(\mathrm{IA})$ are considering pregnancy. Our objective was to survey rheumatologists across Canada about their IA management in pregnancy to identify practice patterns and knowledge gaps.

Methods: We administered an online survey with questions regarding medications for IA treatment including conventional synthetic disease modifying antirheumatic drugs (csDMARDs) and biologics/small molecules in planned and unplanned pregnancies. Email invitations were sent to members of the Canadian Rheumatology Association. We calculated responses frequencies and a priori set a cut-off of $\geq 75 \%$ to define consensus.

Results: Ninety rheumatologists participated in the survey (20\% participation rate); $57 \%$ have been practicing for $>10$ years, $32 \%$ for $\leq 10$ years, and $11 \%$ in training. There was consensus on discontinuation of 4 csDMARDs - cyclophosphamide (100\%), leflunomide (98\%), methotrexate (96\%), and mycophenolate mofetil (89\%) - in planned pregnancies but varied responses on when to discontinue them or what to do in unplanned pregnancies. Respondents agreed that 3 csDMARDs azathioprine (84\%), hydroxychloroquine (95\%), and sulfasalazine (77\%) - were safe to continue in planned and unplanned pregnancies. There was consensus with use of 4 biologics - adalimumab (81\%), certolizumab (80\%), etanercept (83\%), and infliximab (76\%) - in planned pregnancies but uncertainty on when they should be discontinued and their use in unplanned pregnancies.

Conclusions: This national survey shows consensus among rheumatologists on the use of some csDMARDs and biologics/ small molecules in IA patients planning pregnancy but varied knowledge on when to discontinue and what to do in unplanned pregnancies.
\end{abstract}

Keywords: Pregnancy, Inflammatory arthritis, Rheumatic diseases, Survey

\section{Background}

Inflammatory arthritides (IA), which include rheumatoid arthritis (RA) and systemic lupus erythematosus (SLE), are chronic autoimmune diseases that disproportionately affect females more than males [1], often with peak incidences during reproductive years [2]. Although, historically some IA were recognized to improve during pregnancy, particularly RA [3], recent evidence suggests remission during

\footnotetext{
* Correspondence: mdevera@mail.ubc.ca

${ }^{1}$ University of British Columbia, Faculty of Pharmaceutical Sciences, Vancouver, BC, Canada

${ }^{2}$ Arthritis Research Centre of Canada, Richmond, BC, Canada

Full list of author information is available at the end of the article
}

pregnancy in less than $20 \%$ of women with RA [4]. Consequently, it is estimated that $40-50 \%$ of women with IA require treatment throughout the perinatal period $[5,6]$.

Managing IA pregnancy is an important clinical challenge. A 2013 UK survey of rheumatologists and obstetricians showed no uniform practice for using IA medications during pregnancy. Although, no cut-off was used to define response consensus, $80 \%$ of respondents indicated continuation of hydroxychloroquine and over $98 \%$ advised discontinuation of methotrexate and leflunomide [7]. Additionally, over $92 \%$ of respondents indicated discontinuation of anti-tumour necrosis factor agents (anti-TNFs) and rituximab [7]. Since practice patterns differ across health care

(c) The Author(s). 2019 Open Access This article is distributed under the terms of the Creative Commons Attribution 4.0 International License (http://creativecommons.org/licenses/by/4.0/), which permits unrestricted use, distribution, and reproduction in any medium, provided you give appropriate credit to the original author(s) and the source, provide a link to the Creative Commons license, and indicate if changes were made. The Creative Commons Public Domain Dedication waiver (http://creativecommons.org/publicdomain/zero/1.0/) applies to the data made available in this article, unless otherwise stated. 
systems, these findings may not be generalizable. Guidelines for perinatal use of antirheumatic drugs, including conventional synthetic disease modifying anti-rheumatic drugs (csDMARDs) and biologics, have been published in 2016 [8-10]. We surveyed rheumatologists across Canada about their management of IA pregnancy to achieve objectives of identifying consensus among respondents and establishing practice patterns.

\section{Methods}

\section{Survey design}

The survey on rheumatologists' management of IA pregnancy was developed, pretested, and piloted among rheumatologists, expert researchers, and specialist clinicians. The survey consisted of 23 general and specific questions focusing on the use of csDMARDs $(n=12$; azathioprine, chloroquine, cyclophosphamide, cyclosporine, doxycycline, gold salts, hydroxychloroquine, leflunomide, methotrexate, minocycline, mycophenolate mofetil, and sulfasalazine), biologics/ targeted small molecules $(\mathrm{n}=12$; abatacept, adalimumab, anakinra, apremilast, certolizumab, etanercept, golimumab, infliximab, rituximab, tocilizumab, tofacitinib, and ustekinumab), non-steroidal anti-inflammatory drugs (NSAIDs; celecoxib, ibuprofen, and naproxen) and prednisone. For questions on respondents' general knowledge of medication safety, a 3-point Likert scale was used ("safe throughout pregnancy", "safe during certain trimesters", "not safe at all") along with a "not sure" option. Specific questions assessed respondents' treatments of planned and unplanned pregnancies; for the latter, a scenario of an IA patient with a 6-week unplanned pregnancy was employed. Multiple choice options captured how long before conception or when during pregnancy a rheumatologist would discontinue a medication in planned pregnancies. Multiple choice options were also used to capture what respondents would do in unplanned pregnancies ("continue drug, continue pregnancy", "stop drug, continue pregnancy", "continue drug, counsel regarding termination", "stop drug, counsel regarding termination", and "not sure"). The complete survey is in Additional file 1.

\section{Survey administration and analysis}

Members of the Canadian Rheumatology Association (CRA), including rheumatologists and rheumatology trainees, were invited to participate in the survey, available in English and French and hosted online using Fluid Surveys (Ottawa, Ontario). The CRA sent unique email invitations describing the purpose of the survey and number of questions, to 450 members with two reminders in March 2016 (Additional file 2). Respondents provided consent prior to survey commencement. Anonymized responses were exported after survey completion and kept for 5 years. We used descriptive statistics, namely calculated counts and frequencies of survey responses, and a priori set cut-off of $>75 \%$ respondents to define consensus. With no prior survey studies to model defining consensus, we drew from a 2014 systematic review describing how consensus is operationalized in Delphi studies, which reported the most common definition was percent agreement, with $75 \%$ being the median threshold [11].

This study was reviewed and approved by the University of British Columbia Behavioural Research Ethics Board (\#H14-02123).

\section{Results}

All together 96 CRA members accessed the survey, 90 consented to participate (20\% participation rate), and 68 provided responses to all questions (76\% completion rate); nonetheless, all responses were analyzed. Table 1 summarizes respondent characteristics. Over half of respondents (57\%) have been practicing rheumatology for over 10 years, $32 \%$ for less than 10 years, and $11 \%$ were trainees. The majority of respondents worked in an academic/teaching hospital setting (69\%) and spent at least half of their time in direct patient care with IA patients $(51 \%)$. Finally, $43 \%$ and $8 \%$ of respondents reported that the majority $(26-50 \%$ and over $50 \%$, respectively) of their IA patients were women of childbearing years, and $87 \%$ of respondents reported they continue to care these patients for during pregnancy.

\section{Conventional synthetic DMARDs}

When queried on their general knowledge of medications safety during pregnancy (question 11), respondents achieved consensus on 4 csDMARDs that were considered not safe at all: leflunomide (98\%), methotrexate (98\%), cyclophosphamide (95\%), and mycophenolate mofetil (82\%) (Table 2). Regarding which csDMARDs respondents stop for IA patients planning pregnancy (question 15), consensus was achieved for the same 4: cyclophosphamide (100\%), leflunomide (98\%), methotrexate (96\%), and mycophenolate mofetil (89\%) (Fig. 1). The timescale in Fig. 1illustrates responses to how long before conception these 4 csDMARDs are discontinued (question 16). There was consensus among $82 \%$ of respondents on stopping methotrexate at least 3 months before pregnancy. Further, the majority of respondents indicated cyclophosphamide and mycophenolate mofetil should be discontinued at least 3 months before pregnancy; however, responses for timing leflunomide discontinuation were varied, which may reflect variability regarding the use of a cholesteryamine washout.

Two csDMARDs were agreed to be safe during pregnancy, hydroxychloroquine (93\%) and azathioprine $(81 \%)$, based on responses to general knowledge of medication safety (question 11). Near consensus was achieved with chloroquine and sulfasalazine with $74 \%$ 
Table 1 Characteristics of rheumatologists who completed the survey

\begin{tabular}{|c|c|}
\hline Characteristics & $N(\%)^{a}$ \\
\hline \multicolumn{2}{|l|}{ Sex $(n=87)$} \\
\hline Female & $50(58)$ \\
\hline Male & $37(43)$ \\
\hline \multicolumn{2}{|l|}{ Province $(n=87)$} \\
\hline Ontario & $27(31)$ \\
\hline Alberta & $21(24)$ \\
\hline Quebec & $14(16)$ \\
\hline British Columbia & $11(13)$ \\
\hline Nova Scotia & $4(5)$ \\
\hline Saskatchewan & $3(3)$ \\
\hline Manitoba & $3(3)$ \\
\hline New Brunswick & $3(3)$ \\
\hline Newfoundland/Labrador & $1(1)$ \\
\hline \multicolumn{2}{|l|}{ Practice setting $(n=88)$} \\
\hline Academic/teaching hospital & $61(69)$ \\
\hline Group community practice & $13(15)$ \\
\hline Solo community practice & $9(10)$ \\
\hline Other, specify ${ }^{\mathrm{b}}$ & $5(6)$ \\
\hline \multicolumn{2}{|c|}{ Percent of time spent seeing patients $(n=87$ ) } \\
\hline$<25 \%$ & $11(13)$ \\
\hline 25 to $50 \%$ & $15(17)$ \\
\hline 51 to $75 \%$ & $24(28)$ \\
\hline$>75 \%$ & $37(43)$ \\
\hline \multicolumn{2}{|c|}{ Years spent practicing rheumatology $(n=87)$} \\
\hline Currently in training & $10(11)$ \\
\hline 5 years or less & $17(19)$ \\
\hline 6 to 10 years & $11(13)$ \\
\hline 11 to 20 years & $17(20)$ \\
\hline$>20$ years & $32(37)$ \\
\hline \multicolumn{2}{|c|}{$\begin{array}{l}\text { Proportion of patients with inflammatory } \\
\text { arthritis }(n=86)\end{array}$} \\
\hline$<25 \%$ & $2(2)$ \\
\hline 25 to $50 \%$ & $15(17)$ \\
\hline 51 to $75 \%$ & $49(57)$ \\
\hline$>75 \%$ & $20(23)$ \\
\hline \multicolumn{2}{|c|}{$\begin{array}{l}\text { Proportion of inflammatory arthritis patients } \\
\text { that are women of childbearing age }(n=87)\end{array}$} \\
\hline 0 & $0(0)$ \\
\hline 1 to $25 \%$ & $43(49)$ \\
\hline 26 to $50 \%$ & $37(43)$ \\
\hline 51 to $75 \%$ & $5(6)$ \\
\hline$>75 \%$ & $2(2)$ \\
\hline
\end{tabular}

Refer pregnant inflammatory arthritis patients or those considering pregnancy to an "expert" colleague $(n=87)$
Table 1 Characteristics of rheumatologists who completed the survey (Continued)

\begin{tabular}{lc}
\hline Characteristics & $N(\%)^{\mathrm{a}}$ \\
\hline Yes & $33(38)$ \\
No & $54(62)$ \\
Follow inflammatory arthritis patients \\
during pregnancy $(\mathrm{n}=87)$ \\
Yes \\
No & $76(87)$ \\
\hline a calculated on completed responses; ${ }^{\text {b }}$ Others included: rheumatology \\
trainee, not practicing, community with academic and research 'agenda', \\
subspecialized academic clinic, and mixed academic/solo community practice
\end{tabular}

and $70 \%$ of respondents, respectively, considering them safe (Table 2). Regarding medications respondents continue during planned pregnancies (question 15), there was consensus with hydroxychloroquine (95\%) azathioprine (84\%), and sulfasalazine (77\%) (Fig. 2). Finally, concerning when during pregnancy these csDMARDs are discontinued (question 16), respondents agreed hydoxychloroquine (94\%), azathioprine (76\%), and sulfasalazine $(73 \%)$ can be continued throughout pregnancy (Fig. 2).

Finally, Table 3 summarizes responses for managing IA in patients with a 6-week unplanned pregnancy. Variability in survey responses suggest limited consensus; particularly, no consensus was reached regarding which csDMARDs respondents would stop. Agreement was achieved for 3 csDMARDs that respondents would continue during an unplanned pregnancy hydroxychloroquine (91\%), azathioprine (80\%), and sulfasalazine $(77 \%)$.

\section{Biologics/small molecules}

Responses for general knowledge of biologics/small molecule safety during pregnancy suggest uncertainty (question 12); the only consensus achieved was $80 \%$ and $77 \%$ of respondents, respectively, indicating being unsure about apremilast and tofacitinib safety, reflecting the recentness of their introduction into the market (Table 2). In contrast, when asked questions regarding biologic/small molecules use in IA patients planning pregnancy (question 18), we observed consensus for continuation of 4 : etanercept (83\%), adalimumab (81\%), certolizumab (80\%), and infliximab (77\%) (Fig. 3). However, there was response variability regarding when during planned pregnancy rheumatologists would discontinue these biologics (Fig. 3). Finally, the summarized responses for managing IA in patients with a 6-week unplanned pregnancy (Table 3) show no consensus on biologics/small molecules use.

\section{Other medications}

When asked about general knowledge of other medications safety during pregnancy, 84 and $83 \%$ agreed 
Table 2 Respondents' general knowledge on the safety of conventional synthetic disease modifying anti-rheumatic drugs, biologics/small molecules, and other medications in the management of inflammatory arthritis in pregnancy

\begin{tabular}{|c|c|c|c|c|}
\hline & $\begin{array}{l}\text { Safe throughout pregnancy } \\
\text { (\% of respondents) }\end{array}$ & $\begin{array}{l}\text { Safe during certain trimesters } \\
\text { (\% of respondents) }\end{array}$ & $\begin{array}{l}\text { Not safe at all (\% } \\
\text { of respondents) }\end{array}$ & $\begin{array}{l}\text { Not sure (\% } \\
\text { of respondents) }\end{array}$ \\
\hline \multicolumn{5}{|c|}{$\begin{array}{l}\text { Conventional synthetic disease } \\
\text { modifying anti-rheumatic drugs }\end{array}$} \\
\hline Azathioprine & $80.5^{*}$ & 4.9 & 12.2 & 2.4 \\
\hline Chloroquine & 74.1 & 1.2 & 8.6 & 16.0 \\
\hline Cyclophosphamide & 0 & 3.7 & $95.1^{*}$ & 1.2 \\
\hline Cyclosporine & 28.0 & 6.1 & 42.7 & 23.2 \\
\hline Doxycycline & 2.4 & 4.9 & 59.8 & 32.9 \\
\hline Gold salts & 28.7 & 2.5 & 33.8 & 35.0 \\
\hline Hydroxychloroquine & $92.7^{*}$ & 4.9 & 1.2 & 1.2 \\
\hline Leflunomide & 0 & 0 & $97.6^{*}$ & 2.4 \\
\hline Methotrexate & 0 & 1.2 & $97.6^{*}$ & 1.2 \\
\hline Minocycline & 0 & 4.9 & 53.1 & 42.0 \\
\hline Mycophenolate mofetil & 2.5 & 2.5 & $81.5^{*}$ & 13.6 \\
\hline Sulfasalazine & 70.4 & 8.6 & 18.5 & 2.5 \\
\hline \multicolumn{5}{|l|}{ Biologics/small molecules } \\
\hline Abatacept & 9.8 & 9.8 & 15.9 & 64.6 \\
\hline Adalimumab & 37.0 & 32.1 & 6.2 & 24.7 \\
\hline Anakinra & 9.9 & 6.2 & 16.0 & 67.9 \\
\hline Apremilast & 0 & 1.2 & 18.5 & $80.2^{*}$ \\
\hline Certolizumab & 61.0 & 15.9 & 4.9 & 18.3 \\
\hline Etanercept & 43.9 & 29.3 & 7.3 & 19.5 \\
\hline Golimumab & 37.8 & 25.6 & 11.0 & 25.6 \\
\hline Infliximab & 37.8 & 30.5 & 8.5 & 23.2 \\
\hline Rituximab & 8.5 & 8.5 & 25.6 & 57.3 \\
\hline Tocilizumab & 11.0 & 8.5 & 19.5 & 61.0 \\
\hline Tofacitinib & 1.2 & 1.2 & 21.0 & $76.5^{*}$ \\
\hline Ustekinumab & 4.9 & 6.1 & 18.3 & 70.7 \\
\hline \multicolumn{5}{|l|}{ Other medications } \\
\hline Celecoxib & 0 & 54.9 & 29.3 & 15.9 \\
\hline Ibuprofen & 1.2 & $83.6^{*}$ & 14.5 & 1.2 \\
\hline Naproxen & 2.4 & $82.9^{*}$ & 11.0 & 3.7 \\
\hline Other NSAIDs & 1.2 & 67.5 & 22.5 & 8.8 \\
\hline
\end{tabular}

*Indicates consensus among respondents based on a priori cut-off of $\geq 75 \%$

that ibuprofen and naproxen, respectively, were safe during certain trimesters (Table 2). However, when asked specific questions about medications that respondents stopped in IA patients planning pregnancy, no consensus was observed with NSAIDs. Conversely, 91\% of respondents indicated they do not stop prednisone in planned pregnancies. In specific questions regarding unplanned pregnancies, there was no consensus regarding NSAIDs but $85 \%$ of respondents agreed that they would continue prednisone and pregnancy (Table 3).

\section{Guidance needed by respondents}

The final question asked respondents to indicate issues missed by survey questions or other areas regarding IA treatment during pregnancy that they wish further guidance on. Overall, 32 (36\%) respondents provided unique responses to this section and indicated that they needed more nuanced guidance for patient-specific considerations when making decisions concerning medication management and pregnancy in female IA patients. They listed disease type and severity, availability of high-resolution ultrasound for monitoring fetal development, gestational 


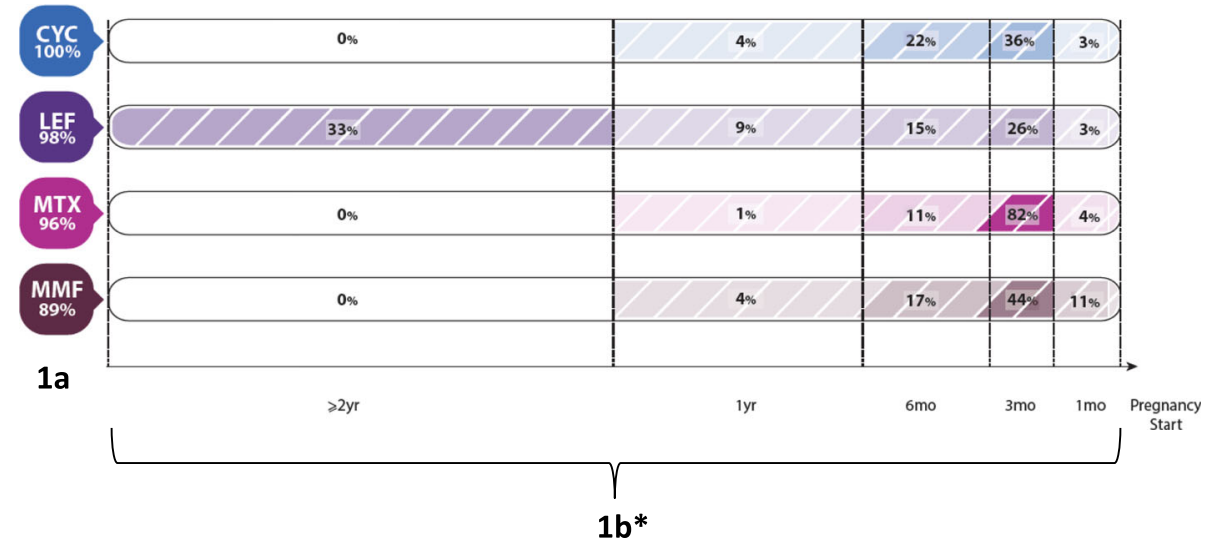

Fig. 1 a Consensus on csDMARDs respondents stop in IA patients planning pregnancy (question 15) and (b) Responses to question on how long before conception they are stopped (question 16) (*numbers do not add to $100 \%$ as other response options are not on a time-scale [e.g. 'do not stop', 'not sure']). Abbreviations: CYC - cyclophosphamide; LEF - leflunomide; MTX - methotrexate; and MMF - mycophenolate mofetil

age, delivery type, continued medication use, and plan to breastfeed as considerations for making changes in disease management and counselling on pregnancy progression. Respondents were interested in the impact of medications used in male partners on pregnancy outcomes. Given the prevalence of anti-inflammatory medication use in IA, respondents hoped for more guidance on considerations for NSAID and prednisone use throughout pregnancy if needed for disease management and for restarting medications post-pregnancy. Respondents mentioned patient non-adherence as a barrier to disease and pregnancy management. They further stressed the need for shared decision making with patients when counselling on the risks of pregnancy continuation.

\section{Discussion}

This national rheumatologist survey focused on knowledge of medication safety, primarily csDMARDs and biologics/ small molecules, and respondents' practice in planned and unplanned pregnancies. There was consensus on discontinuation of 4 csDMARDs (cyclophosphamide, leflunomide, methorexate, and mycophenolate mofetil) in planned pregnancies but limited knowledge on when to stop them prior to pregnancy and no consensus for unplanned pregnancies. Respondents agreed that 3 csDMARDs (azathioprine, hydroxychloroquine, and sulfasalazine) were safe in all pregnancies. There was consensus for using 4 biologics/ small molecules (adalimumab, etanercept, certolizumab, and infliximab) in planned pregnancies but uncertainty on when to discontinue them and no consensus in unplanned pregnancies. There was consensus with prednisone use in planned and unplanned pregnancies but uncertainty regarding NSAIDs.

Our survey informs rheumatologists' practice patterns for IA treatment in pregnancy with implications for identifying gaps in knowledge and research. Guidance for the use of antirheumatic drugs before and during pregnancy from the European League Against Rheumatism (EULAR)

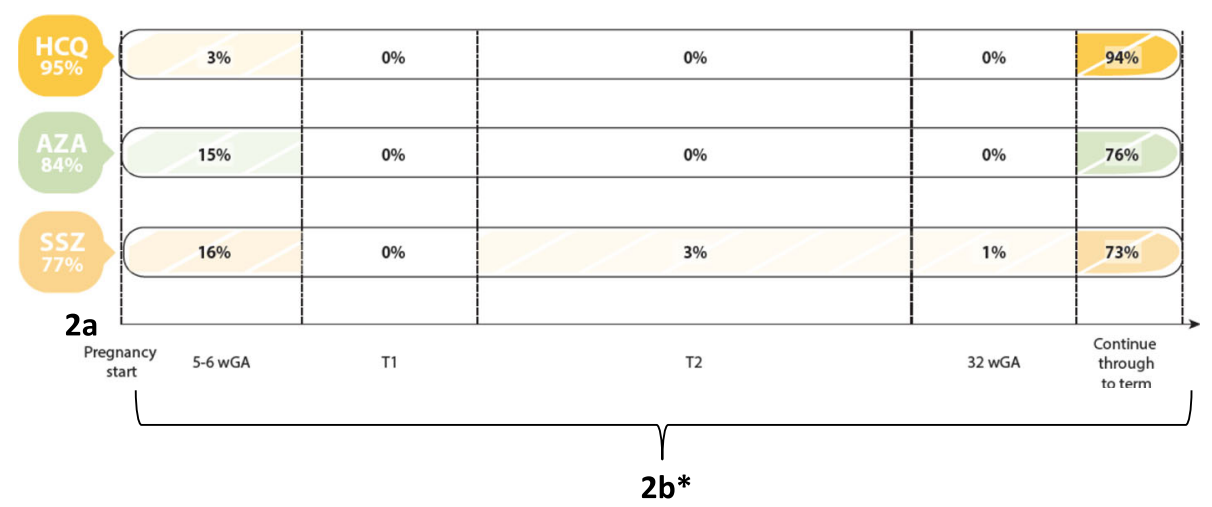

Fig. 2 a Consensus on csDMARDs respondents continue in IA patients planning pregnancy (question 15) and (b) Responses to question on when during pregnancy they are stopped (question 17) (*numbers do not add to $100 \%$ as other response options are not on a time-scale [e.g. 'continue do not stop', 'not sure']). Abbreviations: HCQ - hydroxychloroquine; AZA - azathioprine; SSZ - sulfasalazine 
Table 3 Responses on the management of the inflammatory arthritis in patient with a 6-week unplanned pregnancy with conventional synthetic disease modifying anti-rheumatic drugs, biologics/small molecules, and other medications

\begin{tabular}{|c|c|c|c|c|c|}
\hline & $\begin{array}{l}\text { Continue drug, continue } \\
\text { pregnancy (\%) }\end{array}$ & $\begin{array}{l}\text { Stop drug, continue } \\
\text { pregnancy (\%) }\end{array}$ & $\begin{array}{l}\text { Continue drug, counsel } \\
\text { regarding termination (\%) }\end{array}$ & $\begin{array}{l}\text { Stop drug, counsel } \\
\text { regarding termination (\%) }\end{array}$ & Not sure (\%) \\
\hline \multicolumn{6}{|c|}{ Conventional synthetic disease modifying anti-rheumatic drugs } \\
\hline Azathioprine & $80.3^{*}$ & 6.1 & 1.5 & 4.5 & 7.6 \\
\hline Chloroquine & 71.2 & 7.6 & 3.0 & 0 & 18.2 \\
\hline Cyclophosphamide & 0 & 16.7 & 13.6 & 60.6 & 9.1 \\
\hline Cyclosporine & 27.3 & 18.2 & 1.5 & 19.7 & 33.3 \\
\hline Doxycycline & 0 & 29.2 & 0 & 6.2 & 64.6 \\
\hline Gold salts & 30.3 & 18.2 & 0 & 9.1 & 42.4 \\
\hline Hydroxychloroquine & $90.9 *$ & 4.5 & 1.5 & 0 & 3.0 \\
\hline Leflunomide & 0 & 16.7 & 6.1 & 69.7 & 7.6 \\
\hline Methotrexate & 0 & 22.7 & 7.6 & 65.2 & 4.5 \\
\hline Minocycline & 0 & 34.8 & 0 & 6.1 & 69.7 \\
\hline Mycophenolate mofetil & 3.0 & 19.7 & 10.6 & 47.0 & 19.7 \\
\hline Sulfasalazine & $76.6^{*}$ & 14.1 & 0 & 1.6 & 7.8 \\
\hline \multicolumn{6}{|l|}{ Biologics/small molecules } \\
\hline Abatacept & 24.2 & 45.5 & 1.5 & 6.1 & 22.7 \\
\hline Adalimumab & 66.7 & 25.8 & 1.5 & 1.5 & 4.5 \\
\hline Anakinra & 15.2 & 39.4 & 1.5 & 4.5 & 39.4 \\
\hline Apremilast & 4.6 & 35.4 & 0 & 6.2 & 53.8 \\
\hline Certolizumab & 63.1 & 26.2 & 1.5 & 0 & 9.2 \\
\hline Etanercept & 69.7 & 24.2 & 0 & 1.5 & 4.5 \\
\hline Golimumab & 60.6 & 28.8 & 1.5 & 1.5 & 7.6 \\
\hline Infliximab & 60.0 & 29.2 & 1.5 & 1.5 & 7.7 \\
\hline Rituximab & 18.2 & 39.4 & 1.5 & 6.1 & 34.8 \\
\hline Tocilizumab & 18.2 & 39.4 & 1.5 & 4.5 & 36.4 \\
\hline Tofacitinib & 3.0 & 31.8 & 0 & 7.6 & 57.6 \\
\hline Ustekinumab & 13.8 & 33.8 & 1.5 & 4.6 & 46.2 \\
\hline \multicolumn{6}{|l|}{ Other medications } \\
\hline Celecoxib & 39 & 56 & 0 & 0 & 3 \\
\hline Ibuprofen & 64 & 33 & 0 & 0 & 3 \\
\hline Naproxen & 65 & 32 & 0 & 0 & 3 \\
\hline Prednisone & $85^{*}$ & 12 & 0 & 0 & 3 \\
\hline
\end{tabular}

*Indicates consensus among respondents based on a priori cut-off of $\geq 75 \%$

[8] and from the British Society for Rheumatology (BSR) and British Health Professionals in Rheumatology (BHPR) on prescribing csDMARDs and biologics in pregnancy [9], were both published in 2016, at the time of our survey administration. Consequently, survey responses may reflect understanding of these guidelines or, given the brief period between their publication and our survey's administration, baseline practice patterns for future evaluation of the impacts of these guidelines. Nonetheless, survey responses align with EULAR points for discontinuation of methotrexate, cyclophosphamide, and mycophenolate mofetil before pregnancy and continuation of antimalarials, azathioprine, and sulfasalazine. Regarding biologics/small molecules, the EULAR guidance support use of anti-TNFs during the start of pregnancy, with certolizumab and etanercept use being acceptable throughout pregnancy as they have little transplacental passage. While survey responses regarding biologics/small molecules continuation in planned pregnancies largely aligned with these guidelines, medication discontinuation during pregnancy is not fully addressed by the EULAR points. Furthermore, the EULAR points do not address actions in unplanned pregnancies for which we observed uncertainty for 9 of 12 csDMARDs and all 12 biologics/small molecules queried. 


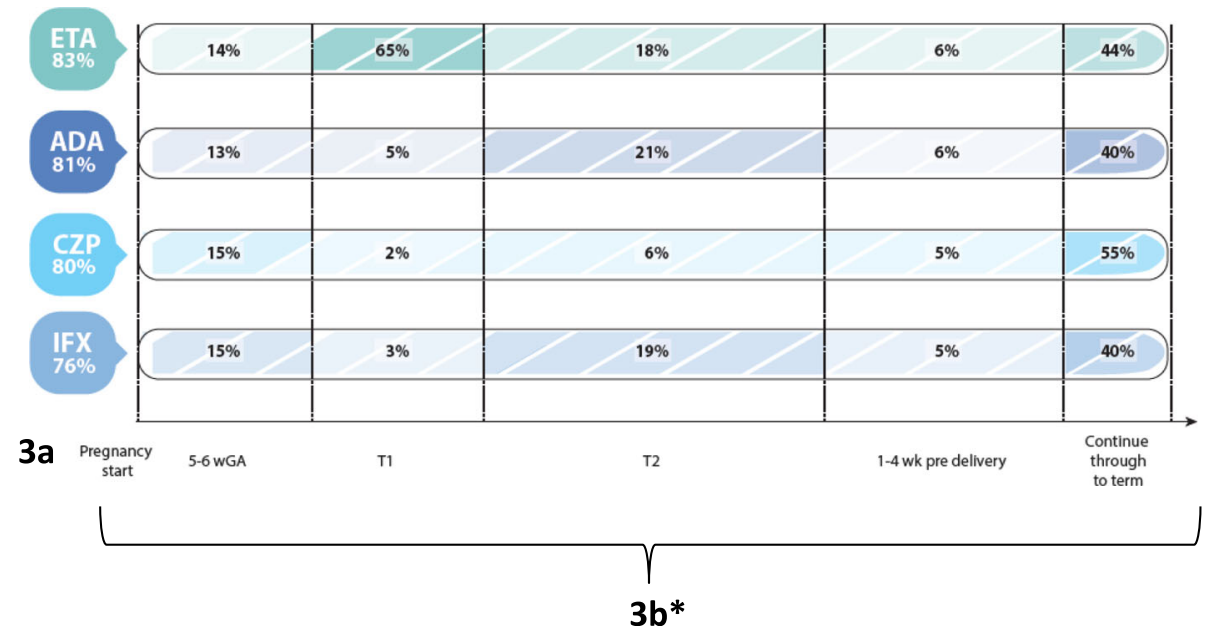

Fig. 3 a Consensus on biologics respondents continue in IA patients planning pregnancy (question 18) and (b) Responses to question on when during pregnancy they are stopped (question 20) (* numbers do not add to 100\% as other response options are not on a time-scale [e.g. 'do not stop', 'not sure']). Abbreviations: ETA - etanercept; ADA - adalimumab; CZP - certolizumab; IFX - infliximab

The BSR BHPR guidelines address gaps in the EULAR points, particularly when medications should be discontinued. For csDMARDs incompatible with pregnancy, cyclosporine should not be used peri-conception, methotrexate should be stopped 3 months before conception, and mycophenolate mofetil 6 weeks in advance [9]. Leflunomide was suggested to only be compatible during peri-conception if accompanied by a cholestyramine washout regimen [9]. Survey responses for the discontinuation of methotrexate aligned with these generally more conservative guidelines. Further, responses on azathioprine, hydroxychloroquine and sulfasalazine use align with the BSR BHPR guidelines for their continuation during pregnancy. Among TNF-alpha inhibitor biologics, only certolizumab was recommended for use throughout pregnancy, golimumab had no data to support any recommendations, and all others were recommended for first trimester (infliximab) or first and second trimester use only (etanercept and adalimumab) [9]. The BSR BHPR guidelines acknowledged the lack of evidence to support recommendations for non-TNF alpha inhibitor biologics/small molecules but stated unintentional first trimester exposure to these drugs would unlikely be harmful [9]. While these guidelines address gaps observed in our survey for biologics/small molecules use in planned pregnancies, the BSR BHPR guidelines largely do not address medication use in unplanned pregnancies, only touching on methotrexate and leflunomide in 'accidental' pregnancies. Given that up to $50 \%$ of pregnancies are unplanned [12], our survey points to potential areas needing attention in future guideline work.

Multiple factors may explain the variability of survey responses. When treating maternal illness in pregnancy, disease severity and potential disease effect on pregnancy outcomes need to be balanced against potential treatment risks to developing fetus. Active IA, particularly RA, psoriatic arthritis and ankylosing spondylitis, can damage joints and lead to maternal disability if untreated [13, 14]. Furthermore, active IA, particularly RA, can have adverse effects on pregnancy outcome (small for gestational age infants and premature delivery) $[13,14]$. Thus, it is important that maternal disease activity be controlled before and during pregnancy with medications that are safe for the fetus. If maternal disease is in remission or has low disease activity, no or little treatment may be required. Each rheumatologist and patient must decide together the severity of maternal disease activity and balance it against the risk of adverse pregnancy outcomes and potential fetal harm. Patient comfort levels taking medication during pregnancy also needs addressing. Additionally, response variability may be due to relative lack of data regarding medication use in pregnancy compared to the non-pregnant state. It is unethical to perform prospective, double-blind, randomized controlled trials of medications safety in pregnancy. There may be animal data on the effect of some drugs which may or may not be applicable to humans. As such, the only method to obtain drug data in human pregnancies is when a mother becomes pregnant while taking a medication or takes one during pregnancy and the outcomes of the pregnancy and fetus are documented. Further, to collect a sufficient number of case reports of pregnancies exposed to a particular medication requires it be on the market for many years. For new medications, there will be almost no data available on that drug in human pregnancies. Lack of data from prospective randomized trials leaves a gap in knowledge regarding the medication safety in pregnancy, especially newer medications. Some clinicians are satisfied with less observational 
data and others require more before prescribing drugs in pregnancy; as such, there are variable levels of comfort among prescribers. These aforementioned reasons may be more relevant to explaining survey responses for planned pregnancies. With unplanned pregnancies, such reasons apply along with considerations on values and beliefs around termination of pregnancy.

Limitations of our survey study deserve comment. First, despite centralized invitation from the CRA, the sample size was small and participation rate (20\%) was modest. However, the aforementioned survey of UK rheumatologists on DMARDs use during pregnancy similarly yielded a $20 \%$ response rate [7]. Additionally, prior surveys to CRA membership using the same methods have yielded similar response rates $[15,16]$. With $69 \%$ of respondents representing rheumatologists practicing in academic or teaching hospital settings, findings may be subject to potential selection bias. Despite querying 12 csDMARDs, 12 biologics/small molecules, 3 NSAIDs, and prednisone, our survey omitted some medications covered by the EULAR points (e.g. tacrolimus) and BSR BHPR (e.g. belimumab). In addition, survey scenarios with planned and unplanned pregnancies in IA patients queried did not incorporate disease activity or severity, which are important considerations. Finally, our survey did not ask rheumatologists about recommendations made to patients after delivery, specifically, regarding breastfeeding.

\section{Conclusion}

This national survey shows consensus among rheumatologists on the safety of some csDMARDs and biologics/ small molecules in IA patients planning pregnancy. However, there was limited knowledge on when to discontinue these medications and what to do in unplanned pregnancies. Findings are timely as they establish baseline practice patterns and identify gaps that may be addressed by recently published points and guidelines.

\section{Additional files}

Additional file 1: Rheumatologist Survey on the Management of Inflammatory Arthritis in Pregnancy (PDF 210 kb)

Additional file 2: Survey invitations sent via email to Canadian Rheumatology Association members (English and in French) (PDF 49 kb)

\section{Abbreviations}

ADA: Adalimumab; anti-TNFs: Anti-tumour necrosis factor agents; AZA: Azathioprine; BHPR: British Health Professionals in Rheumatology; BSR: British Society for Rheumatology; CRA: Canadian Rheumatology Association; csDMARDs: Conventional synthetic disease modifying antirheumatic drugs; CYC: Cyclophosphamide; CZP: Certolizumab; DMARDs: Disease modifying antirheumatic drugs; ETA: Etanercept; EULAR: European League Against Rheumatism; HCQ: Hydroxychloroquine; IA: Inflammatory arthrides; IFX: Infliximab; LEF: Leflunomide; MMF: Mycophenolate mofetil; MTX: Methotrexate; NSAIDs: Non-steroidal antiinflammatory drugs; RA: Rheumatoid arthritis; SLE: Systemic lupus erythematosus; SSZ: Sulfasalazine; TNF: Tumour necrosis factor; UK: United Kingdom

\section{Acknowledgements}

We would like to thank all the physicians who took time to complete our survey and share their opinions, as well as the Canadian Rheumatology Association (CRA) for making this study possible. We would also like to thank Claire McGowan for the continuous support in launching, maintaining and closing the survey.

\section{Funding}

This research was funded by an operating grant from The Arthritis Society (YIO-13-07). The funding body had no role in the design of the study, the collection, analysis, and interpretation of data, and in writing the manuscript. Dr. De Vera is Canada Research Chair in Medication Adherence, Utilization, and Outcomes and is recipient of The Arthritis Society Network Scholar Award and Michael Smith Foundation for Health Research Scholar Award. Dr. Hazlewood is supported by a CIHR New Investigator Salary Award and The Arthritis Society Young Investigator Salary Award.

\section{Availability of data and materials}

The datasets used and/or analysed during the current study are available from the corresponding author on reasonable request.

\section{Authors' contributions}

All authors were involved in drafting the article or revising it critically for important intellectual content. MDV had full access to all of the data in the study and takes responsibility for the integrity of the data and the accuracy of the data analysis. Study conception and design: MDV, CB, GSH, SE. Acquisition of data. CB, NWT, AH, SE. Analysis and interpretation of data. MDV, CB, NWT, AH, GSH, NR, SE. All authors read and approved the final manuscript.

Ethics approval and consent to participate

Reviewed and approved by the University of British Columbia Behavioural Research Ethics Board (\#H14-02123). All participants provided written consent to participate.

\section{Consent for publication}

Not applicable.

\section{Competing interests}

The authors declare no competing interests.

\section{Publisher's Note}

Springer Nature remains neutral with regard to jurisdictional claims in published maps and institutional affiliations.

\section{Author details}

${ }^{1}$ University of British Columbia, Faculty of Pharmaceutical Sciences, Vancouver, BC, Canada. ${ }^{2}$ Arthritis Research Centre of Canada, Richmond, BC, Canada. ${ }^{3}$ Collaboration for Outcomes Research and Evaluation, Vancouver, BC, Canada. ${ }^{4}$ Division of Rheumatology, Department of Medicine, Faculty of Medicine, University of British Columbia, Vancouver, BC, Canada. ${ }^{5}$ Cumming School of Medicine, University of Calgary, Calgary, AB, Canada.

Received: 20 November 2018 Accepted: 25 April 2019

Published online: 17 May 2019

\section{References}

1. Whitacre CC, Reingold SC, O'Looney PA, et al. A gender gap in autoimmunity task force on gender, Multiple Sclerosis and Autoimmunity. Science. 1999:283:1277-8.

2. Badley EM, Kasman NM. The impact of arthritis on Canadian women. BMC Womens Health. 2004:4(Suppl 1):S18

3. Marder W, Littlejohn EA, Somers EC. Pregnancy and autoimmune connective tissue diseases. Best Pract Res Clin Rheumatol. 2016:30:63-80.

4. de Man YA, Dolhain RJEM, van de Geijn FE, Willemsen SP, Hazes JMW. Disease activity of rheumatoid arthritis during pregnancy: results from a nationwide prospective study. Arthritis Rheum. 2008;59:1241-8. 
5. Clowse MEB. Lupus activity in pregnancy. Rheum Dis Clin N Am. 2007;33: 237-52.

6. Østensen M, Förger F. Management of RA medications in pregnant patients. Nat Rev Rheumatol. 2009:5:382-90.

7. Panchal S, Khare M, Moorthy A, Samanta A. Catch me if you can: a national survey of rheumatologists and obstetricians on the use of DMARDs during pregnancy. Rheumatol Int. 2013;33:347-53.

8. Gotestam Skorpen C, Hoeltzenbein M, Tincani A, et al. The EULAR points to consider for use of antirheumatic drugs before pregnancy, and during pregnancy and lactation. Ann Rheum Dis. 2016;75:795-810.

9. Flint J, Panchal S, Hurrell A, et al. BSR and BHPR guideline on prescribing drugs in pregnancy and breastfeeding-part I: standard and biologic disease modifying anti-rheumatic drugs and corticosteroids. Rheumatology (Oxford). 2016;55(9):1693-7.

10. Flint J, Panchal S, Hurrell A, et al. BSR and BHPR guideline on prescribing drugs in pregnancy and breastfeeding-part II: analgesics and other drugs used in rheumatology practice. Rheumatology (Oxford). 2016;55:1698-702.

11. Diamond IR, Grant RC, Feldman BM, et al. Defining consensus: a systematic review recommends methodologic criteria for reporting of Delphi studies. J Clin Epidemiol. 2014;67:401-9.

12. Black AY, Guilbert E, Hassan F, et al. The Cost of Unintended Pregnancies in Canada: Estimating Direct Cost, Role of Imperfect Adherence, and the Potential Impact of Increased Use of Long-Acting Reversible Contraceptives. J Obstet Gynaecol Canada. 2015;37:1086-97.

13. Zbinden A, van den Brandt S, Ostensen M, Villiger PM, Forger F. Risk for adverse pregnancy outcome in axial spondyloarthritis and rheumatoid arthritis: disease activity matters. Rheumatology (Oxford). 2018;30:30.

14. Harris N, Eudy A, Clowse M. Patient-reported disease activity and adverse pregnancy outcomes in systemic lupus erythematosus and rheumatoid arthritis. Arthritis Care Res. 2018;15:15.

15. Fitzcharles M-A, Ste-Marie PA, Clauw DJ, et al. Rheumatologists lack confidence in their knowledge of cannabinoids pertaining to the management of rheumatic complaints. BMC Musculoskelet Disord. 2014;15:258.

16. Grabowski D, Henderson B, Lam D, et al. Attitudes towards subsequent entry biologics/biosimilars: a survey of Canadian rheumatologists. C. Clin Rheumatol. 2015;34:1427-33.

Ready to submit your research? Choose BMC and benefit from:

- fast, convenient online submission

- thorough peer review by experienced researchers in your field

- rapid publication on acceptance

- support for research data, including large and complex data types

- gold Open Access which fosters wider collaboration and increased citations

- maximum visibility for your research: over $100 \mathrm{M}$ website views per year

At $\mathrm{BMC}$, research is always in progress.

Learn more biomedcentral.com/submissions 